\title{
O REGIME DE CÁTEDRA NO ENSINO SUPERIOR: OS PRIMEIROS PROFESSORES DA ESCOLA DE ENGENHARIA INDUSTRIAL DA CIDADE DO RIO GRANDE
}

\author{
Vanessa Barrozo Teixeira ${ }^{1}$ \\ Elomar Callegaro Tambara \\ Universidade Federal de Pelotas (UFPel)
}

\section{RESUMO}

Este trabalho investiga como se constituiu o corpo docente da Escola de Engenharia Industrial (EEI), primeira instituição de ensino superior da cidade do Rio Grande, criada em meados da década de 1950. Tendo como ideia central o regime de cátedra, busca-se compreender como surge a categoria de professor catedrático e como ela se desenvolveu com amplos poderes no ensino superior brasileiro. Apresentando como objeto de análise a EEI e seu corpo docente o artigo tem algumas questões norteadoras, como, por exemplo: Quem foram estes professores? Qual era a sua formação? Estes possuíam experiência docente? Para compreender o viés desta história institucional serão analisados relatórios da EEI, bem como a bibliografia pertinente ao assunto.

Palavras-chave: Regime de cátedra, corpo docente, ensino superior, Escola de Engenharia Industrial.

\section{THE SYSTEM OF CHAIR IN HIGHER EDUCATION: THE FIRST TEACHERS OF THE ESCOLA DE ENGENHARIA INDUSTRIAL OF RIO GRANDE}

\begin{abstract}
This work investigates how was consisted the teaching staff of the Escola de Engenharia Industrial (EEI), the first institution of higher education in Rio Grande, created in the mid-1950s. With the central idea of the system of chair, we seek to understand how there is the category of professor and how it developed with broad powers in brazilian higher education. Presenting as an object of analysis the EEI and its teaching staff the article has some guiding questions such as: Who were these teachers? What was your formation? These had teaching experience? To understand the gore of this institutional history of the EEI reports will be analyzed and the literature pertinent to the subject.

Keywords: System of chair, the teaching staff, higher education, Escola de Engenharia Industrial.
\end{abstract}

\section{Introdução}

O presente artigo trata da constituição do primeiro corpo docente da Escola de Engenharia Industrial (EEI), localizada na cidade do Rio Grande. Este trabalho faz parte de um recorte de pesquisa de dissertação, a qual tem como objeto central de análise a história institucional da EEI. É significativo frisar que a periodização da pesquisa é de 1953 até 1961, período que envolve a criação da escola e sua federalização, ou seja, quando esta passa a ser vinculada ao Ministério da Educação e Cultura (MEC). Todavia, para este artigo serão analisados apenas os primeiros anos da escola, período que antecede a década de 1960.

A Escola de Engenharia Industrial, instituição de ensino superior, criada em 1954, foi a primeira deste gênero no município e a segunda no estado do Rio Grande do 
Sul. Foi mantida por uma entidade de caráter privado, a Fundação Cidade do Rio Grande criada em 1953, justamente com este propósito. No mesmo ano de criação da Fundação é organizada a Congregação dos futuros professores da EEI. Nesta congregação encontravam-se os professores que viriam a ser catedráticos em suas respectivas disciplinas na escola. As aulas propriamente ditas iniciaram apenas em 1956, contudo, durante os anos de 1954 e 1955, a EEI manteve um curso preparatório nas instalações provisórias da instituição que funcionava na Biblioteca Pública Riograndense, voltado para aqueles interessados em ingressar na primeira instituição de ensino superior do município. Os professores do curso eram alguns dos membros da Congregação e ali, muitos iniciaram sua carreira docente, alguns sem nunca terem trabalhado no ensino superior, outros sem nunca terem ministrado uma aula.

É interessante ressaltar que os primeiros professores da EEI mantinham trabalhos paralelos com a docência, atuando principalmente nas empresas e indústrias da cidade. Um dos estabelecimentos industriais que contribuiu para a consolidação da escola, tanto concedendo seus espaços para as aulas práticas como cedendo a maior parte do seu plantel profissional, foi a Ipiranga S/A Companhia Brasileira de Petróleos. $\mathrm{O}$ diretor-superintendente da empresa, o Eng ${ }^{\mathrm{O}}$ Francisco Martins Bastos, "figura paternal" (WERLE, 2004) na história da EEI, além de fazer parte da presidência da Fundação Cidade do Rio Grande, também viria a tornar-se um dos professores catedráticos da escola.

Por meio da análise complexa do que significou o regime de cátedra no ensino superior brasileiro, percebe-se que este foi basilar para a construção dos primeiros estabelecimentos educativos desta categoria no país. Mantendo-se presente, em alguns casos, mesmo após a Reforma Universitária de 1968, a qual criou os departamentos e excluiu a cátedra. Através das particularidades da EEI, como a criação da Congregação e do Conselho Técnico Administrativo (CTA), ambos constituídos por professores catedráticos, pode-se compreender o sentido da cátedra neste espaço escolar e como esse regime se desenvolveu nos primeiros anos da escola.

Para elucidar de forma concisa esse recorte histórico-institucional primeiramente será abordada a questão do regime de cátedra, sua definição e sua presença no ensino superior brasileiro. Em um segundo momento será tratado como surgiu a Congregação de professores, seu papel, os professores integrantes, bem como, a constituição do Conselho Técnico Administrativo (CTA) da EEI, outro importante órgão dirigente dentro da escola. E no último momento serão evidenciadas como se constituiu o corpo docente da EEI, quem foram os primeiros professores, sua formação, bem como sua trajetória docente e profissional.

\section{O regime de cátedra: o poder nas mãos dos professores}

Antes de falar especificamente sobre o corpo docente da EEI, é significativo esclarecer de que forma os professores de ensino superior atuavam no cenário educacional nacional, além de buscar definir o conceito de professor catedrático, conceito tão caro e discutido pela história da educação brasileira. A presença de professores catedráticos no ensino superior brasileiro tem sua origem no período imperial, momento em que surgem os primeiros estabelecimentos de ensino deste nível no Brasil. Para Fávero (2000:1) o regime de cátedra pode ser considerado o "núcleo ou "alma mater" das instituições de ensino superior" no Brasil, tendo como base as primeiras cadeiras de Anatomia e Cirurgia nomeadas por D. João VI no início do século XIX. Segundo Cunha (2007) esse regime administrativo pedagógico tem como referência principal o decreto 1.386, de 28 de abril de 1854, que transformou os cursos jurídicos isolados em faculdades e deu outras providências. Contudo, Fávero (2000) já 
aponta que no Império a partir da Carta de Lei de 11 de agosto de 1827, a qual institui os primeiros cursos jurídicos no Brasil já estava presente a propriedade da cátedra para o ensino público, prevendo a vitalicidade aos professores que seriam nomeados pelo governo após prestarem concursos de provas e títulos.

Dentro dessa nova forma de ensino, surge a presença do professor catedrático, docente responsável por uma cadeira, que seria um sinônimo para disciplina escolar. Nesse período esse professor era denominado como "lente catedrático" e "lecionava a matéria da sua cadeira durante uma vida útil de 25 anos de serviço ativo, após o que era jubilado" (CUNHA, 2007:108, grifo do autor). Assim que o catedrático tivesse concluído sua trajetória docente em uma instituição, era necessário nomear o "lente substituto" que seria o 8professor mais antigo da faculdade, e que através de decreto imperial era nomeado como o catedrático para essa cadeira que precisava ser preenchida. Esses professores substitutos não estavam ligados a disciplinas específicas, fazendo parte de uma "reserva docente" (CUNHA, 2007). Entretanto, deveriam estar disponíveis sempre que surgisse a necessidade do preenchimento de alguma cátedra. Mas, para se tornar "lente substituto" de qualquer faculdade era preciso realizar concursos para o ingresso na instituição, já que apenas o diretor de cada faculdade era nomeado pelo imperador. ${ }^{2}$

A autonomia dos professores catedráticos em relação à instituição que pertencem e ao próprio estado sempre esteve presente, desde o Império. Ser catedrático significava antes de tudo ser um funcionário vitalício que permaneceria em um cargo definitivamente, além de exercer poder pedagógico sobre a cadeira da qual fazia parte. A Reforma Francisco Campos de 1931, define e reitera novas demandas ao professor catedrático, como por exemplo, ratificando que ele deveria continuar sendo considerado o "primeiro na hierarquia do corpo docente" (FÁVERO, 2000:2). Além disso, permitia que candidatos à provimento de cátedra pudessem ingressar nas instituições sem concurso no caso do mesmo ter inventado ou descoberto algo de alta relevância ou publicado obra de valor doutrinário. Todavia, essa indicação deveria partir de um professor catedrático da instituição e seria avaliada por uma comissão. A partir dessa reforma educacional e da Constituição de 1934, o catedrático adquire além da vitalicidade de cargo, o caráter de inamovibilidade, ou seja, garantia a impossibilidade de ser removido sem que o desejasse (GRACIANI, 1984). É importante ressaltar que

\begin{abstract}
A cátedra foi considerada, ainda, como uma "repartição administrativa" do ensino superior e de outros níveis (secundário) e o "legítimo" representante desta unidade escolar era o catedrático, único responsável por tal repartição e pelos docentes que dela faziam parte; poderia ser compreendida, também, como sendo um agrupamento de docentes de determinada área do conhecimento sob a tutela de um único "chefe" - o catedrático - que mantinha todo poder decisório em suas mãos (GRACIANI, 1984:82-83).
\end{abstract}

A autonomia dos catedráticos também influenciava na seleção dos outros professores da instituição, denominados de professores assistentes ou auxiliares. Estes eram escolhidos pelo catedrático, portanto, deveriam ser de total confiança do mesmo afinal estes o auxiliavam com as disciplinas, ministrando aulas sempre que solicitados pelo catedrático. Essa seleção era "resultado quase exclusivo do arbítrio do catedrático, em decisões às vezes tendenciosas e eivadas de autoritarismo" (FÁVERO, 2000: 3). Segundo Graciani (1984) após dois anos no cargo, os professores auxiliares ou assistentes deveriam submeter-se ao concurso de livre-docência, caso contrário, perderiam sua posição. 
Com a Constituição de 1946, mais uma especificidade é agregada ao regime, trata-se da liberdade de cátedra. Esta significava a liberdade de ensino ao professor, não sendo uma exclusividade apenas do catedrático, mas de todos os docentes (GRACIANI, 1984). Mesmo assim, o catedrático exercia cada vez mais um poder centralizador em suas mãos, agregando a si uma figura centralizadora, com interesses demarcados, que possuía uma série de direitos a seu favor. Fávero (2000:7) acredita que eles representavam o "poder saber, o poder do saber e a possibilidade de poder fazer".

O regime de cátedra é extinguido em 1968 com a Reforma Universitária e a criação dos Departamentos, todavia, segundo Celeste Filho respaldado por Chamlian (2006) mesmo com a extinção das cátedras após a reforma, alguns privilégios ainda se mantiveram para os agora denominados "professores titulares", os quais ainda mantinham-se com amplos poderes dentro das universidades. No que diz respeito à EEI até o momento dessa reforma de ensino seus professores seguiram atuando em suas cátedras para o desenvolvimento do ensino de Engenharia na cidade do Rio Grande.

\section{O papel da Congregação e do Conselho Técnico Administrativo da EEI}

Como em muitas instituições de ensino superior a existência de uma congregação de professores era crucial para que elas pudessem efetivamente funcionar ou estarem aptas ao funcionamento. Após a criação da Fundação Cidade do Rio Grande em 1953, era necessário montar o que viria a ser o corpo docente da Escola de Engenharia, mas além de professores, eles necessitariam de um corpo dirigente que estivesse também engajado na manutenção e na administração da escola. Para isso, foram criadas duas esferas administrativas para a escola, a Congregação e o Conselho Técnico Administrativo. A Congregação, constituída por professores catedráticos, tinha amplos poderes para excluir professores que não estivessem cumprindo com as designações necessárias da docência, como, por exemplo, efetuar trabalhos eficientes ou publicações de valor científico, bem como pesquisas voltadas para sua área.

As congregações constituíam a primeira instância de decisão e os catedráticos por sua vez eram seus membros natos. Além disso estiveram sempre entre os que poderiam assumir a direção da escola de que faziam parte, podendo desse modo assumir igualmente cargos administrativos (GRACIANI, 1984:86).

A Escola de Engenharia Industrial possui em seus registros a presença de 29 membros na sua Congregação, em sua maioria engenheiros e integrantes do Conselho Diretor da Fundação Cidade do Rio Grande e do que viria a ser o Conselho Técnico Administrativo da escola. Conforme foi afirmado por Graciani (1984), os professores que faziam parte desse seleto grupo poderiam assumir outras funções além do ofício de professor, o que aconteceu com o primeiro diretor da EEI, o Eng. ${ }^{\circ}$ Cícero Marques Vassão. É relevante lembrar que o cargo de diretor que era designado pela Congregação e tinha um prazo de dois anos, o qual poderia ser reeleito, fato que aconteceu com o Eng. ${ }^{\circ}$ Vassão diretor da escola durante o período de sua criação até sua federalização, em 1961.

As decisões da Congregação eram tanto de caráter didático como administrativo. Assim como afirmado por Graciani (1984:86) "na esfera didática, decidiam sobre programações, horários, manutenção de disciplinas, etc. E na dimensão administrativa iam desde a homologação de nomeações de funcionários até a anulação de contratos". Conforme o Regimento Interno da Escola de Engenharia Industrial, aprovado pela Diretoria do Ensino Superior em maio de 1956, o número de disciplinas que a escola possuía era de 24 . O que leva a crer que o número de professores catedráticos da escola, 
neste período inicial, fosse de 24 , afinal cada disciplina era organizada e regida por um único professor catedrático.

Anísio Teixeira em texto publicado no início da década de 1960, originalmente em inglês com tradução feita por Macioniro Celeste Filho (2006), descrevia o papel da congregação de professores como um dos mais importantes órgãos dentro da escola, sendo ela de nível superior ou não. Além de reforçar a presença dos professores que faziam parte do sistema de cátedras das instituições e que eram os responsáveis pela organização da congregação.

A escola superior, como as demais escolas, pode estar sob o controle
da lei e do governo nos aspectos de organização e finanças, mas no
que se refere ao ensino, o professor tem uma situação inexpugnável. A
"cátedra" é realmente soberana e a "congregação", isto é, a assembléia
dos "catedráticos" é o verdadeiro órgão coletivo de governo da escola.
O professor catedrático é vitalício, intransferível e tem "status"
semelhante ao dos juízes do Supremo Tribunal. São "magistrados" do
"saber", pondo e dispondo soberanamente a respeito do que seja este
"saber" (TEIXEIRA apud CELESTE FILHO, 2006:39).

O Conselho Técnico Administrativo (CTA) é outra esfera importante dentro de uma instituição escolar de ensino superior, sendo considerada a entidade responsável pela organização e redação de documentos, pareceres de ordem didático-pedagógica e regimentos, dentre outras atribuições. Contudo, toda as decisões do Conselho deveriam ser submetidas ao exame da Congregação (GRACIANI, 1984). Vale frisar que os membros da Congregação eram também membros do Conselho Técnico, ou seja, também se compunha de professores catedráticos. O primeiro CTA da EEI foi responsável por criar e manter, nos primeiros anos da escola, um curso preparatório para os interessados em ingressar na instituição. Para isso nomearam professores, escolheram as disciplinas e os programas que seriam ensinados, as bancas examinadoras para os concursos de habilitação (vestibular), bem como dividiram os horários para as aulas que aconteceriam à noite na sede provisória da EEI, no prédio da Biblioteca Riograndense.

Para entender mais especificamente quem foram esses professores e quais eram suas relações com a engenharia, bem como com o setor industrial e empresarial da cidade do Rio Grande é preciso analisar a formação e a trajetória profissional destes indivíduos responsáveis por alicerçar a primeira instituição de ensino superior de um município.

\section{Corpo docente: a formação e a trajetória profissional dos primeiros professores da EEI}

Para tratar sobre a constituição propriamente dita do corpo docente da Escola de Engenharia Industrial é necessário notar que não era uma exigência da instituição que estes possuíssem dedicação exclusiva ao magistério superior, portanto, todos os que ali se encontravam possuíam ocupações profissionais paralelas à atividade docente. Algo que poderia influenciar na decisão dos professores em não se dedicar exclusivamente a carreira docente, era que a mesma ainda estava em construção no que tange a docência no ensino superior (CATANI, 2011). A profissionalização do professor, da categoria profissional ainda estava em voga, principalmente em uma cidade como Rio Grande, que foi ter seu primeiro curso superior em meados da década de 1950. A partir da análise das fichas cadastrais dos primeiros professores da EEI percebe-se que era fundamental que estes possuíssem atividades relacionadas com a especialidade da cadeira, o que reforçava o caráter de comprometimento da escola com as disciplinas 
escolares, com os programas implantados e com o corpo discente que eles viriam a instruir. A seguir será realizada uma compilação dos primeiros professores que atuaram na criação da escola e se mantiveram na instituição durante o período analisada pela pesquisa de dissertação (1953-1961). Dentre os dados levantados encontra-se a formação acadêmica, disciplina escolhida para ministrar, atuação profissional fora da escola, dentre outras informações.

O professor e primeiro diretor da EEI, Cícero Marques Vassão possuía graduação em Engenharia Civil pela Faculdade de Engenharia do Paraná. Foi professor catedrático da cadeira de Cálculo Diferencial Integral e da disciplina de Hidráulica. Sem possuir experiência no magistério, exercia a função de engenheiro chefe do Departamento Nacional de Portos, Rios e Canais, do $18^{\circ}$ distrito, secção de Rio Grande.

O professor Hélio Benjamin Vieira era o único professor formado em Agronomia da EEI. Graduou-se pela Escola de Agronomia e Veterinária da URGS e foi professor catedrático da cadeira de Complementos de geometria analítica, noções de nomografia. Como experiência docente, havia ministrado a disciplina de Matemática para o segundo ciclo do Colégio Estadual Lemos Jr.

O professor Alfredo Huch graduou-se em Engenharia Civil pela Universidade Técnica do RS na década de 1930. Foi professor da disciplina de Geometria descritiva tendo como assistente o Prof. Sérgio Pernigotti. Possuía experiência docente através de sua experiência como professor do Curso Propedêutico da Escola de Comércio Dr. Fernandes Moreira, localizado na cidade do Rio Grande, no qual ministrava as disciplinas de Matemática, Física, Química e História Natural. Concomitante ao trabalho docente, o Eng. ${ }^{\circ}$ Huch trabalhava na Ipiranga S/A Companhia Brasileira de Petróleos. O professor Roberto Bastos Tellechea, sobrinho do Eng ${ }^{\circ}$ Francisco Martins Bastos $^{3}$ havia graduado-se em Engenharia Mecânica e Elétrica pela Universidade Técnica do RS. Não possuía experiência docente, atuando na Ipiranga S.A. Companhia Brasileira de Petróleos. Era o responsável pela cadeira de Resistência dos materiais e grafo - estática, disciplina que ministrava no $2^{\circ}$ ano do curso. O professor João Rocha graduou-se em Engenharia Civil na Escola de Engenharia da URGS e era o responsável pela cadeira de Mecânica. Além dessa disciplina, foi professor assistente da cadeira de Geometria Analítica, trabalhando junto com o Prof. Hélio Benjamin Vieira.

O professor Thomaz Paes da Cunha Filho graduou-se Engenheiro Mecânico na Bélgica na década de 1930. Já havia atuado como professor no Colégio Estadual Lemos Jr e trabalhava como engenheiro chefe da destilaria da Ipiranga S.A. Companhia Brasileira de Petróleos. O professor Fuad Abdalla Nader graduou-se em Ciências Econômicas pela Faculdade de Ciências Econômicas de Pelotas, tendo sido professor da Escola Técnica de Comércio São Francisco, localizada na cidade do Rio Grande, ministrando a disciplina de Contabilidade Industrial. Ministrava a cadeira de Estatística, Economia política e finanças na EEI. O professor Ivo Pereira Braga graduou-se em Engenharia Civil pela Escola de Engenharia da Universidade do Rio Grande do Sul. Sem experiência docente, atuava como Engenheiro Diretor Técnico da Divisão de Rio Grande do Departamento estadual de Portos, Rios e Canais (D.E.P.R.C), Era responsável pela cadeira de Construção Civil, do $4^{\circ}$ ano do curso. O professor Heitor Amaro Barcellos, funcionário da Ipiranga, graduou-se em Engenharia Mecânica e Elétrica pela Escola de Engenharia de Porto Alegre. Foi professor da cadeira de Termodinâmica e motores térmicos para o $5^{\circ}$ ano, que depois modificou-se para Termodinâmica (RELATÓRIO, 1957). Faleceu prematuramente em 1957 (CESAR, 2011), sendo substituído pelo professor Darcy Pedro Piccini. Engenheiro civil graduado pela mesma instituição, mas atuava como engenheiro chefe da Oficina 
Mecânica da Cia. União Fabril. Ministrava também a disciplina de Tecnologia Mecânica e Instalações Industriais.

O professor Francisco Martins Bastos graduou-se Engenheiro Mecânico Eletricista pela Universidade Técnica do RS, em 1928. Foi presidente da Fundação Cidade do Rio Grande, entidade mantenedora da EEI e também Diretor Superintendente da Ipiranga S.A. Companhia Brasileira de Petróleos. Assumiu a cadeira de Organização das indústrias, Contabilidade pública e industrial, Direitos administrativos e Legislação, ministrada no último ano de curso. O professor Fernando Abott Torres também graduado em Engenharia Elétrica e Mecânica, mas no Instituto Eletrotécnico e Mecânico de Itajubá/MG, foi professor da disciplina de Física Industrial e trabalhava na Ipiranga.

O professor Eliézer de Carvalho Rios graduou-se em Química Industrial ${ }^{4}$ pela Escola de Engenharia da URGS. Sua experiência no magistério se resumia ao ensino particular de química, ao passo que exercia a função de chefe do Laboratório Bromatológico da Secretaria da Agricultura e químico do Laboratório de tecnologia do Entreposto de pesca de Rio Grande. Era o responsável pela disciplina de Química Tecnológica e Analítica. Vale lembrar que este professor foi um dos fundadores do primeiro Museu Oceanográfico do município, criado em 1953 pela Fundação Cidade do Rio Grande. O engenheiro Jayme da Motta concluiu sua graduação em Engenharia de Minas e Metalurgia na Escola de Engenharia da URGS, e foi professor da cadeira de Geologia Econômica e Noções de Metalurgia. Sem possuir experiência docente, atuava como engenheiro chefe e Assistente do Diretor da Cia União Fabril, empresa manteve convênio de seis anos com a Fundação Cidade do Rio Grande, concedendo suas instalações industriais para as aulas práticas e estágios dos estudantes da EEI. Tinha como professor assistente, Fernando Duprat da Silva que era formado pela Faculdade de Ciências Exatas, Físicas e Naturais da Universidade de Buenos Aires, Argentina. Foi professor de Física do Colégio Estadual Lemos Jr, trabalhando com a parte de Mineralogia e Geologia.

O professor Irineu Soares de Souza Filho formado em Química Industrial pela Escola de Engenharia da URGS, possuía experiência docente como professor de Física do Colégio Estadual Lemos Jr e tornou-se professor dessa disciplina na EEI, presente já no primeiro semestre do curso. O professor Reinaldo Pereira de Oliveira Maia, também era graduado em Química Industrial, mas formou-se no Curso de Química da Escola de Engenharia de Pernambuco. Atuava como Químico do Ministério da Agricultura na chefia do Laboratório de Análises de Vinha, na cidade do Rio Grande, e ministrava a disciplina de Eletroquímica.

O engenheiro civil Paulo de Castro Moreira graduou-se na Escola de Engenharia da URGS e era professor catedrático da disciplina de Topografia. Era engenheiro na Ipiranga e tinha como professores assistentes, o professor Arthur Américo de Oliveira Ehlers, engenheiro civil formado pela Escola de Engenharia da URGS e que também não possuía experiência docente, o professor José Mabilde Ripoll que trabalhava como engenheiro encarregado da secção de Pelotas do $18^{\circ}$ distrito do DEPRC e o professor Mário Alquati. Este havia graduado-se recentemente em Engenharia Mecânica Elétrica e Civil, pela Escola de Engenharia da URGS. Em abril de 1956 o professor Alquati é transferido para assistente da cadeira de Cálculo Infinitesimal, de responsabilidade do professor catedrático, Cícero Vassão ${ }^{5}$.

Os professores das disciplinas de Química da EEI eram todos graduados pelo Instituto de Química Industrial da Escola de Engenharia da Universidade do Rio Grande do Sul. Eram eles: João Câncio de Miranda Jr, João Rubem de Oliveira Almeida, Edmaro da Silva Abrantes e Glasphyra Monteiro Piffero. Com exceção da 
professora Glasphyra, que era chefe do Laboratório da Cia União Fabril, todos os demais químicos trabalhavam nos laboratórios da Ipiranga S/A.

O professor Ruy Honório Bacellar graduado em Engenharia Civil pela Escola de Engenharia da URGS, ficou com a disciplina de Materiais de Construção, Tecnologia e Processos Gerais de construção. Trabalhava como engenheiro chefe da divisão do Departamento de Portos, Rios e e Canais do Estado do RS. O professor Olavo Kramer da Luz, com semelhante graduação era o professor catedrático da disciplina de Desenho a mão livre, presente já no primeiro semestre do curso de Engenharia. Possuía além da graduação um curso de especialização em Arquitetura e Desenho Técnico pela Escola Técnica Parobé, pertencente à Escola de Engenharia da URGS. Atuava como desenhista da Secretaria das obras públicas e do DEPRC. O professor João Kramer de Lima, engenheiro eletricista-mecânico formado pela Universidade Técnica do RS, atuava na disciplina de Desenho Técnico. Era ex-chefe do Serviço Riograndino de Eletricidade. O professor Edy Paulo Pereira dos Santos também formado em Engenharia Civil em Porto Alegre, veio a ministrar a disciplina de Cálculo Diferencial e Integral, cadeira que pertencia ao professor catedrático Cícero Marques Vassão. Além disso, havia ministrado as disciplinas de Matemática e Física no curso científico do Colégio Manuel Ribas em Santa Maria.

O professor Álvaro José Fernandes, era Engenheiro Mecânico formado na Escola de Engenharia de Oldenburg, na Alemanha. Ministrava a disciplina de Metalurgia com desenvolvimento de Siderurgia. O professor Fernando Bezerra Bertolli, engenheiro civil e mecânico eletricista, graduado na Escola de Engenharia da URGS, era Engenheiro Chefe das oficinas da Viação Férrea do RS, em RG e responsável pela disciplina de Mecânica aplicada, bombas e motores hidráulicos.

$\mathrm{O}$ primeiro corpo docente da EEI, formado por professores catedráticos e assistentes, possuía uma formação variada, inclusive com graduações realizadas no exterior, como Argentina e Alemanha. Por meio dessa análise pode-se notar que tratavase de um grupo de profissionais atuantes e consolidados em suas respectivas áreas, tendo a carreira docente como um novo desafio, um verdadeiro diferencial para o período principalmente tratando-se de ensino superior. $\mathrm{O}$ fato de conseguirem consolidar o trabalho técnico com a docência reforça a importância desses sujeitos para a consolidação da EEI, uma instituição que inicia sua trajetória em 1954 sem possuir estrutura física e sendo mantida por uma entidade privada.

\section{Considerações finais}

Após analisar e elencar algumas possíveis questões e hipóteses sobre a constituição do corpo docente da primeira instituição de ensino superior da cidade do Rio Grande, criada na década de 1950, pode-se perceber alguns fatores cruciais para a consolidação desse grupo de professores. A cátedra, ligada ao poder docente e dirigente, pode ter sido um importante meio de influência para que estes engenheiros passassem a dedicar parte do seu tempo de trabalho para o magistério, afinal a autonomia dentro da instituição favorecia o professor, deixando-o livre para organizar sua disciplina e sua prática escolar.

Outro fator fundamental que pode ter sido levado em consideração é a ligação mais do que direta do diretor-superintendente da Ipiranga S/A Companhia Brasileira de Petróleos e também presidente da Fundação Cidade do Rio Grande, Eng ${ }^{\circ}$ Francisco Martins Bastos com a EEI. O envolvimento dessa figura na criação e na trajetória da escola pode ter sido algo que "motivou" os demais engenheiros que atuavam na empresa Ipiranga a também se dedicarem ao ensino de engenharia na EEI. Um detalhe importante é a presença de uma única mulher, a Prof ${ }^{a}$ Glasphyra Monteiro Piffero, que 
trabalhava na Companhia União Fabril e ministrava a disciplina de Química inorgânica na EEI. O que deixa claro que existia uma hegemonia masculina no corpo docente da escola, além de poucas mulheres profissionais da área atuando na cidade do Rio Grande.

Sobre a cátedra, é preciso ressaltar que apesar de todo poder depositado na figura do catedrático é necessário reconhecer que estes foram os preconizadores do ensino superior brasileiro e que através do ensino por eles ministrado foi possível organizar as instituições que por muito tempo se mantiveram isoladas e seguindo diferentes perspectivas dentro de suas organizações e conhecimentos. Com a Escola de Engenharia Industrial não foi diferente, ela tem em sua origem e trajetória a presença de professores que trabalharam em regime de cátedra por muitos anos, até a transferência da escola para a universidade em 1969.

\section{Referências}

CATANI, Denise Barbara. Estudos de história da profissão docente. In: 500 anos de educação no Brasil. 5ª edição. Belo Horizonte: Autêntica, p. 585-599, 2011.

CELESTE FILHO, Macioniro. A constituição da Universidade de São Paulo e a reforma universitária da década de 1960. São Paulo: PUC, 2006, 293F. Tese (Doutorado em Educação: História, Política e Sociedade). Programa de Pós-Graduação em Educação, Pontifícia Universidade Católica de São Paulo.

CESAR, Willy. Chico Bastos, o pescador. Rio de Janeiro: UniverCidade, 2011.

CUNHA, Luiz Antonio. A universidade temporã: o ensino superior, da Colônia à Era Vargas. São Paulo: Editora UNESP, 2007.

FÁVERO, M. L. A. Da Cátedra Universitária ao Departamento: subsídios para discussão. In: 23 Reunião Anual da ANPEd, 2000, Caxambú-MG. Anais da 23 ${ }^{\mathbf{a}}$

Reunião da ANPEd, 2000. Acessado em 27-11-11; Disponível em: 〈http://www.anped.org.br/reunioes/23/textos/1118t.PDF>.

GRACIANI, Maria Stela Santos. O ensino superior no Brasil: A estrutura de poder na universidade em questão. Petrópolis: Ed. Vozes, 1984.

HASSEN, Maria de Nazareth; FERREIRA, Maria Letícia Mazzucchi. Escola de Engenharia/UFGRS - Um século. Porto Alegre: Tomo editorial, 1996.

REGIMENTO da Escola de Engenharia Industrial. Fundação Cidade do Rio Grande, Rio Grande: Artes Gráficas RIO GRANDE Ltda, 1956.

RELATÓRIO de Inspeção da Escola de Engenharia Industrial da cidade do Rio Grande. Fundação Cidade do Rio Grande, 1954.

RELATÓRIO de Reconhecimento da Escola de Engenharia Industrial da cidade do Rio Grande. Fundação Cidade do Rio Grande, 1957.

RELATÓRIO do $2^{\circ}$ período letivo da Escola de Engenharia Industrial da Fundação Cidade do Rio Grande. Dr. Ruy Poester Peixoto (Inspetor Federal). Rio Grande, janeiro de 1961. 
WERLE, Flávia Obino Corrêa. História das instituições escolares: de que se fala? In: LOMBARDI, José Claudinei; NASCIMENTO, Maria Isabel Moura (orgs.). Fontes, história e historiografia da educação. Campinas: Autores Associados, 2004, p. 13-35.

Recebido em agosto-12

Aprovado em fevereiro-13

\section{Notas}

${ }^{1}$ Bacharel em Museologia (UFPel); Mestranda do Programa de Pós-Graduação em Educação (PPGE) da Faculdade de Educação da Universidade Federal de Pelotas (UFPel)

${ }^{2}$ Segundo Cunha (2007) o governo poderia nomear um substituto caso não houvesse candidatos para o preenchimento de vagas.

${ }^{3}$ Roberto Bastos Tellechea era filho de João Francisco Tellechea, um dos fundadores da Ipiranga S.A. Companhia Brasileira de Petróleos, e Felisbina Bastos Tellechea, irmã de Francisco Bastos Tellechea (Relatório de Inspeção, 1954:335).

${ }^{4}$ O curso de Química Industrial é alterado para Engenharia Química em 1955 (HASSEN; FERREIRA, 1996).

${ }^{5}$ Dados retirados do Relatório de Reconhecimento da EEI de 1957. Acervo do Arquivo Geral da FURG. 